\title{
Cognitive Approach of Vocabulary Learning
}

\author{
Bianqi Sun \\ Department of Foreign Language \\ Beijing Institute of Graphic Communication \\ Beijing, China
}

\begin{abstract}
Vocabulary learning is one of the most important components for any language learners. According to my college English teaching experience, vocabulary knowledge is closely and frequently associated with language fluency, which poses the biggest headache for foreign language learners, including the college students of intermediate level. This paper aims to offer some strategies of vocabulary acquisition with the help of two powerful cognitive tools---metaphor and metonymy, which are traditionally treated as figurative speech for language decoration. Considering that most English words are polysemous to some extent, this paper also discusses the relationship between core meaning and extended meanings, and the collocation of combined words---chunks.
\end{abstract}

Keywords-vocabulary learning; polysemy; metaphor; metonymy; chunk

\section{INTRODUCTION}

In the context of globalization, there has been an increasing need for talents with high English proficiency. For Chinese college students, though they have learned English for at least twelve years (most students start learning English in the first year of their primary school, while others may start from the beginning of preschool education), yet few of them can express themselves freely due to the limits of inadequate vocabulary. Vocabulary is of primary importance in language teaching and in linguistic communication, but it has not always been adequately emphasized or given adequate attention to. According to my interview and free talk with the students, they all admit one of the most important challenges that they face in foreign language learning is learning vocabulary. Vocabulary has been recognized as crucial to language use in which their insufficient knowledge of vocabulary may lead to difficulties in their foreign language learning. There are various reasons for this, but improper teaching method is more or less responsible for the unsatisfactory situation. In the history of vocabulary teaching, attention has mainly centered on the teaching of words as isolated or de-contextualized items (Howatt, 2004; Kelly, 1969; Schmitt, 2000). More specifically, the teaching and learning of vocabulary lists has been one of the pillars in the classroom for centuries. Apart from the above mentioned, in learning foreign language vocabulary, students need to be trained to use appropriate vocabulary learning strategies with the cognitive approach.

\section{VOCABULARY LEARNING STRATEGIES}

Modern technology has made it possible to learn a foreign language in a virtual space with the easiest convenience. All the learning materials are accessible to them for free. Yet the computer and internet can never automatically improve students' language achievement, and the nature of learning process seems never to change with time. The modern technology facilitates the process of learning, but the key factor lies in the learners themselves. Acquiring a foreign language involves different areas such as motivation, learners' practical needs, learning environment, learning Strategies and language awareness.

According to Chen Meihua(2009), most studies in the area of language leaning strategies have fixed on specific aspects of vocabulary acquisition, such as contextual guessing, wordpart-formation, form-meaning association, note taking, English-English dictionary use, and rote repetition. Thus, for example, repetition as a strategy was much more frequently used than were strategies requiring complex manipulation of information. Nation(1982) noted that tools involving rote memory, such as wordlists, were considered effective in enhancing the acquisition of a great deal of vocabulary in a short period of time, Gu and Johnson (1996) reported that learners' vocabulary size was related to the ability to make skillful use of a dictionary and to the willingness to invest time on practicing newly learned words and Cohen and Aphek(1980) found that there was a link between proficiency and association skills, with higher levels of proficiency being associated with greater capacity to apply association s kills.

Schmitt further categorized vocabulary learning strategies into five subcategories, namely.

- Determination strategies: these are individual learning strategies, and the most important ones. Without concrete goal in mind, no one can be so determined in implementing the painstaking task.

- Social strategies: these are the strategies when learners learn new words through interaction with others; For Chinese ESL learners, they don't have a right speaking environment except limited class hours, thus "dumb and deaf" English is still the biggest problem. Moreover, constant output can digest what has been input.

- Memory strategies: these are the strategies whereby learners link their learning of new words to mental processing by associating their existing or background knowledge with the new words. 
- Cognitive strategies: these are the strategies that do not engage learners in mental processing but are more mechanical means.

- Metacognitive strategies: these are the strategies related to processes involved in monitoring, decisionmaking, and evaluation of one's progress.

In the history of language learning and teaching, various strategies have been put forward, and all of them seem to be plausible. Needless to say, strategies vary from individual to individual. Choose one that suits you the best.

\section{WHAT IS POLYSEMY}

Before answer this question, I'd like to make it clear that in the philosophical sense English words are all polysemous. According to the origin and history for polysemy, "from French polysémie (1897), from Medieval Latin polysemus, from Greek polysemos "of many senses," from poly- (see poly-) + sema 'sign' (see semantic)".Generally speaking, a word has not only a denotation but also connotation. When emotional and affective things are involved, the core meaning of a word will be extended and transferred. Cognitively, any concept is ambiguous, and accordingly the features of a concept could be numerous. Take the word SPRING as an example, the basic meaning and the frequently used meaning is "the season after winter and before summer, in which vegetation begins to appear, in the northern hemisphere from March to May" (http://www.oxforddictionaries.com/definition/english/spring). In some dictionaries, more than 40 sense items of SPRING are given. But we can see clearly that the separate meanings are logically related to each other, though we may not be able to identify how the senses have been exactly extended diachronically. Yet it does not hinder us to create an image about the happenings in the season of spring: temperature rises; all plants come out of ground overnight; many things suddenly springs up; it is the mating season for some animals and insects; and in some countries spring is considered as the right season to make a decision for the coming year, etc. In this way can we easily associate the numerous meanings together and take them as a semantic family. In the English class, very few students can tell more than four meanings of the word SPRING. The following reasons might well account for this phenomenon.

- In high school, their sole goal is the entrance examination, and text book only tells the corresponding Chinese equivalent.

- High school English teachers have no motivation to make the learning complex by telling the students the mechanism of meaning extension, which helps little for the improvement of the examination scores.

- Cognitive linguistics is a relatively new discipline; some of the English teachers may not be trained in this field.

Whatever the reasons are, as discussed above, learning of polysemy is not only necessary but also crucial for vocabulary expansion. The focus of vocabulary expansion should be more put on the in-depth understanding of a word.
In fact, as is noted above, almost all the words in language are polysemous to a greater or lesser extent. Polysemy, the phenomenon whereby a linguistic unit exhibits multiple distinct yet related meanings is a very common feature of any language. Polysemy is justly considered to be a necessary means of language economy. Conversely thinking, we may say the word is used in different contextualized setting.

It is acknowledged polysemy is pervasive in language and appears in many forms. It is not just an accident of history or of synchrony, but rather an essential manifestation of the flexibility, adaptability, and richness in meaning potential.

With regard to the interpretation of polysemy, the English word LAMB may refer to, among other things, a young sheep. Based on the principle of similarities, the literal meaning is extended metaphorically to "a person easily deceived or cheated", "a sweet innocent mild-mannered person". Till this point, it has become a polysemous word. With the passage of time and its flexible uses in different contexts, it picks up other meanings like "the flesh of a young domestic sheep eaten as food", which is grounded on the metonymic principle of Animal For Food.

From the example, we can see how the meanings are invented functionally and figuratively.

Éva Kovács (2011) AsÉva Kovács note, a word may have both a 'literal' meaning and one or more 'transferred' meanings, although we cannot determine with precision how many different meanings a given word may have altogether.

Conversely, polysemes are etymologically and therefore semantically related, and typically originate from metaphoric/metonymic usage (e.g. bank as a building and a financial institution). The distinction is, however, not always straightforward, especially since words that are etymologically related can, over time, drift so far apart that the original semantic relation is no longer recognizable.

The treatment of polysemy in cognitive linguistics can be characterized as involving.

- The adoption of a view of meaning as categorization, all the meanings are taken as a semantic field or category.

- The meanings are created contextually and the distinctions of the meanings are not clearly divided. Some meanings not only refer to the concrete physical object, but also the invoked abstract mental concepts.

- The meaning extension is metaphorically or metonymically done based on similarities or contiguity.

According to the questionnaire conducted for the college students, if not specially trained in this field, cannot well recognize and identify the relationships among the meanings, and some even have never noticed the association. Johanna Viimaranta(2012) claims we cannot prove that all native speakers see the relationship between different meanings of a polysemous word alike. According to the Conceptual Theory of Metaphor and Metonymy, the different meanings of a polysemous unit can have a common metaphorical conceptualization or their metaphorical conceptualizations can 
be related to one another. This means that seemingly unrelated meanings can be cognitively related and this connection can explain the existence of such expressions.

In this part, I'd like to notice the difference between polysemy and homonyms. Polysemy may be vaguely contrasted with homonymy, the phenomenon of two words with unrelated meanings having, by accident, the same pronunciation. As it happens, the English spelling DATE (and its pronunciation) may also represent another word, which refers to the fruit that grows on a date palm. The meaning of this word is clearly unrelated to the meanings of the word date "point in time; appointment; person with whom one has an appointment". The two words are homonyms. Similarly, we take BANK1(The land alongside or sloping down to a river or lake) and BANK2(A financial establishment that uses money deposited by customers for investment, pays it out when required, makes loans at interest, and exchanges currency) as homonyms, and in most dictionaries, they are listed as separate lexical items, but according to the research of some cognitive linguists, they have proved the intrinsic relationship and begun to regard it as a polysemous word, with the first meaning as the basic meaning. The same is true with the word PUPIL, which has two seemingly unrelated meanings: a. a person, usually young, who is learning under the close supervision of a teacher at school, a private tutor, or the like; student; b. the expanding and contracting opening in the iris of the eye, through which light passes to the retina. The second meaning might stem from the tiny reflection in the pupils. It does not matter much to view the word pupil as a polyseme or homonym. What is important is that it deepens the thinking of the meanings.

\section{METAPHOR, METONYMY AND POLYSEMY}

The three words are put together here because they are closely connected. The extension of the meanings in a polyseme is either metaphorical or metonymic. Metaphor and metonymy here are more than decorative figure of speech; actually, they are cognitive modes of thinking and tools.

Metonymy In metonymic extensions one meaning is not used as a model for another and there is no relationship of mapping or similarity established between vehicle and target. Rather, a linguistic element, instead of holding its typical reference, refers to something contiguous, either actually contiguous in space and time, or conceptually contiguous. Standard examples of metonymic relations are cause/effect, part/whole, possessor/possessed, container/contained,- - any meaning extension that led from one member of these pairs to another would be classed as metonymic. By the way, the transformation in part of speech of a word is also classed as metonymic. And in the eyes of cognitive linguists, compared with metaphor, metonymy is more basic.

Analysis based on metaphor and metonymy has become increasingly common in discussions of lexical semantics, but it faces a challenge because of the distinction on which it depends between 'core' and 'extended' senses.

Metaphors involve a crossing between perspectives that select similarities (identical features) and differences under each of the perspectives chosen; metonymies involve a crossing between perspectives directed towards contiguous parts of situations and objects.

Traditionally viewed, metonymy is a figure of speech in discourse used for rhetorical effect. It is a stylistic language operation that makes use of the name for one thing to replace that of something else. For instance, in "there were a lot of new faces at the party, "the word faces is the name used to refer to people in this particular context. With the advent of cognitive linguistics, completely different assumptions were made about the nature of metonymy as well as metaphor (Gibbs, 1994; Lakoff, 1987; Lakoff \& Johnson, 1980).

Perhaps the most important difference between metaphor and metonymy is that metaphors often involve hypothetical thinking... metonymy does not involve hypotheses. Perhaps we can explain this difference by pointing out that metonymy is based on relations that presuppose actual coincidence, whereas metaphor, which involves finding a match for an attribute among all the mentally stored attributes, is freed from constraints of what could actually occur or coincide(Warren, 1999, p. 131).

Metaphor is based on a mapping between mental domains - source and target. It is important for understanding how semantic meaning is made and extended. Although a metaphor usually derives from language, its properties are based in a mode of thought that extends beyond the linguistic. Metonymy, too, is best understood as a mode of thought, often derived from language, but based on patterns of association in other minds, having the function of substitution and reference.

The two most important tropes in rhetoric, poetics, and everyday language are metaphor and metonymy, which are pervasive and deeply rooted in people minds. Defining what they are is difficult and different definitions easily lead to contradictions, but, generally, metaphor and metonymy can be understood as special processes of meaning-making. Metaphor and metonymy make it possible to combine different conceptual domains to convey meaning. Etymologically speaking, metaphor transfers meaning from one conceptual domain to another, while metonymy renames one thing with a name from the same conceptual domain. This meaning-making need not necessarily be tied to language and verbal expression, but can also appear in visual art(Karin Kukkonen(2008).

The above famous scholars have made distinctions between the two tropes. The wording might be slightly different, but basic difference is metaphor happens on the cross-mapping of two similar domains, while metonymy highlights the salience and contiguity. Through the following example we hope to shed light on the differences.

Take the word FACE as an example. As a noun, face has about twenty meanings. But we can roughly divide the meanings into two groups. 1. The front part of a person's head from the forehead to the chin, or the corresponding part in an animal. 2. The surface of a thing, especially one that is presented to the view or has a particular function, in particular. For instance, "An expression shown on the face" is considered as metonymic, while "a vertical or sloping side of a mountain or cliff"," The plate of a clock or watch bearing the digits or hands" are classed as metaphorical. The latter is based on the 
seminaries, while the former is based on contiguity, demonstrating the metonymic principles: Part for Whole; Cause for Effect.

\section{CHUNK ACQUISITION}

The concept of chunks was first proposed by Becker (1976) and Bolinger(1975) in the mid-1970s. Chunks, different from the phrases, are loosely integrated blocks of functions and forms, with both vocabulary and grammatical features of language structure.

Chunks can be roughly divided into four types.

- Polywords. Fixed phrases composed by more than one word may be either a typical structure of the Englishtype specification, such as by the way, a piece of a cake etc., all in all etc.

- Institutionalized expressions. It can be expression in the form of a sentence type in spoken language, fixed or semi-fixed form, fixed combination of pragmatic functions of words, or complete sentences; it can also be fixed form at the beginning of the sentence, including proverbs, aphorisms and social formula language, like How do you do?.

- Phrasal constraints. It refers to a phrase framework constituted by certain fixed words. Such as, a... ago, a long time ago; the...-er, the...-er structures.

- Sentence builders. It is in the form of fixed or semifixed phrases with syntactic features, appropriate words or clauses can be added as needed, for example, "It is universally acknowledged that ...", "There is no doubt that ..."

Broadly speaking, vocabulary learning scope should be widened to phrases, fixed expressions, and loose collocations. They are words grouped together (connected items or words) so that they can be stored or processed as single concepts. Collocation is central to the lexical approach because the way words combine in collocations is fundamental to all language use.

Lewis (2000) stresses on the importance of learning the patterns of collocations because much of the spoken and written language comprises them. We need to add the concept of collocational competence to our thinking as it aids us in avoiding errors in our language. With chunks stored in mind, correct sentences can be easily and quickly made up.

Chunk is not just limited to vocabulary, but also covers a wide scope of collocation, either lexical or syntactic. Actually, many of the chunks have the function of discourse conjunction and cohesion. Moreover, the use of chunks will also increase the power to reason, stimulating them to think and write in a logic way.

Linguists believe that native speakers store chunks in their mental lexicon to retrieve and use them in their language. Also, he states that the ability to chunk language successfully is central to an understanding of how language works.
For this reason, Lewis suggests that language teaching should include the teaching of lexical phrases or chunks. In fact, he advocates that lexical phrases in any language offer more communicative and expressive power than grammatical structures. He further stresses that without chunking acquisition, comprehension and production of the language will be limited and slowed down.

Lewis holds that noticing lexical chunks in the language is a prerequisite for learning language. He argues that increased awareness helps in converting input to intake. Added to consciousness-raising, he feels that importance should be given to developing the ability to chunk the language.

Collocation is central to the lexical approach because the way words combine in collocations is fundamental to all language use. Lewis stresses on the importance of learning the patterns of collocations because much of the spoken and written language comprises them. Hill says that we need to add the concept of collocational competence to our thinking as it aids us in avoiding errors in our language.

According to Nation (2001), strengthening the formmeaning connection involves having to recall a meaning when seeing or hearing a particular word or having to recall a spoken or written form when wanting to express a meaning. The subjects must be able to recognize a word and link it to its meaning by using L1 translations.

In my view, lexical approach is to focus the attention on the word blocks to build language system. The principles of the chunk teaching can be summarized as follows: (1) Vocabulary and grammar are not separated; language is not composed of the grammar system, but rather consists of multiple chunks. (2) Teachers should not analyze or translate the target language, but to guide the students to focus on chunk learning and repetitive use. (3) The vocabulary and grammar should be treated as an integrated part to learn. It's advisable that vocabulary learning be implanted into sentences.

\section{CONCLUSION}

This paper expounds on vocabulary learning, we may sum up the idea we are advocating in this paper as the following. Vocabulary plays a vital role in language learning. Broadly speaking, all vocabularies are more or less polysemous. Polysemy can be viewed as a lexical field composed of the multiple meanings, which are semantically and historically related. The meaning extension of a lexical unit is not only a semantic phenomenon but also a cognitive processing. The relatedness of the meaning indicate that the non-literal meanings are not picked up arbitrarily. Language is not only a mirror of world, but also a reflection of the world based on human mode of thought. Metaphor and metonymy, as powerful tools, can well help people understand the extended meanings. And chunk or collocation learning can boost and improve the efficiency of sentence making. With the right learning strategies, students can acquire a good command of vocabulary. 


\section{ACKNOWLEDGMENTS}

This research is supported by the Social Science Research Common Program of Beijing Municipal Commission of Education (No. 18190114/004); the Major Teaching \& Reform Program of Beijing Institute of Graphic Communication (No. 22150115033); the Program for Science Development and Foreign Language Education of Guangxi Academy of Social Sciences(No. GXSLXM-15-05); the Discipline Construction and Postgraduate Education Program of Beijing Municipal Commission of Education (No. 21090116020)

\section{REFERENCES}

[1] Howatt, A.P.R. with Widdowson, H. G. (2004). A History of English Language Teaching, Oxford: Oxford University Press.

[2] Kelly, L. G. (1969). 25 Centuries of Language Teaching. NY: Newbury House Publishers.

[3] Schmitt, N. (2000). Vocabulary Learning Strategies. In N. Schmitt and M. yicC\&rXhy, Vocabulary: Description, Acquisition and Pedagogy. Cambridge: Cambridge University Press.

[4] ChenMeihua. Vocabulary learning strategies and language games: Reporting on a Taiwan-based study Journal of Maori and Pacific Development 10:1 February, 2009 52-73.

[5] Nation, I.S.P.(1982).Beginning to learn foreign vocabulary: a review of the research.RELCJournal,13(1) ,14-37.

[6] Gu,Y., \& Johnson, R. K.(1996). Vocabulary leaming strategies and language leaming outcomes. Language Learning, 46, 643-679.

[7] Cohen,A.D., \& Aphek, E. (1980). Retention of second language vocabulary over time; investigating the role of mnemonic associations. System, 8, 221-235.

[8] Éva Kovács (2011). Polysemy in Traditional vs. Cognitive Linguistics. Eger Journal of English Studies XI 3-19.

[9] Johanna Viimaranta(2012). The metaphors and metonymies of domination: explaining the different meanings of the Russian prefixpod-. Russ Linguist (2012) 36:157-174.

[10] Gibbs,R.(1994).Thepoeticsofmind:Figurativethought,languageandunder standing.Cambridge,

[11] England:CambridgeUniversityPress.

[12] Lakoff, George. 1987. Women, Fire and Dangerous Things: What Categories Reveal about the Mind? Chicago: University of Chicago Press.

[13] Lakoff, G., \& Johnson, M. (1980).Metaphors we live by. Chicago: Chicago University Press.

[14] Warren, B. (1999). Aspects of referential metonymy. In K. Panther \& G. Radden (Eds.),Metonymy in language and thought(pp. 121-138). Philadelphia: John Benjamins.

[15] Karin Kukkonen(2008). Beyond Language: Metaphor and Metonymy in Comics Storytelling. English Language Notes46.2 (89-97).

[16] Becker J. 1976. The Phrasal Lexicon. Mass: Bolt J.: and New man.

[17] Bolinger, D. 1975. Aspects of Language. Harcourt Brace Jovanovich.

[18] M. Lewis. 2000. "Teaching collocation: further developments" in The Lexical Approach, M. Lewis, Ed. Hove: Language Teaching Publications.

[19] Nation, I. S. P.2001. Learning Vocabulary in Another Language. Cambridge: Cambridge University Press. 